\title{
Knowledge Management in the Energy Sector: Review and Future Directions
}

\section{John S. Edwards}

Contact details:

Professor John S Edwards

Operations and Information Management Group

Aston Business School

Aston University

Aston Triangle

Birmingham

B4 7ET

United Kingdom

e-mail: j.s.edwards@aston.ac.uk

Tel: +44 (0)121 2043087

Fax: +44 (0)121 2043210 


\title{
Knowledge Management in the Energy Sector: Review and Future Directions
}

\author{
Abstract \\ Purpose \\ To examine the state of knowledge management in the energy sector and more \\ broadly, and consider future directions for research and practice. \\ Methodology/Approach \\ By reviewing the literature on knowledge management and the practice of knowledge \\ management as relevant to the energy sector.

\section{Findings} \\ There are many examples of good practice in knowledge management in the sector, \\ and some organisations, especially in the oil industry, are seen as leaders in KM \\ practice. However, other organisations have yet to embark on explicit KM initiatives \\ or projects at all. In addition, some parts of the energy sector discuss KM without any \\ reference to the more general KM literature.

\section{Originality/value of paper} \\ Although some parts of the energy sector have justifiably earned a good reputation for \\ knowledge management, other parts are completely unaware of the field, as is \\ apparent from the literature. This review helps to raise awareness and guide future \\ work.
}

Key words: communities of practice, information systems, knowledge management Category: General review.

\section{Introduction}

Knowledge is central to the strategy and operations of most organisations in the energy sector, and comes in many different forms - whether it is scientific knowledge (petroleum chemistry), technological knowledge (how to run generator sets efficiently), or management knowledge (how to motivate your staff to introduce new operating practices). Even at the extraction end of the value chain, where competitive advantage might be based on simple availability of a resource, there is still a need for scientific and technological knowledge just to operate successfully.

Managing the knowledge in an organisation, at least as an implicit activity, is almost certainly as old as organisation themselves. The term "knowledge management" (KM) was coined in the 1980s by Karl Wiig, and became popular as a recognised field of study in the 1990s, partly as a result of books such as those by Nonaka and Takeuchi (1995), and Davenport and Prusak (1998). Nevertheless, the roots of KM as an explicit activity go much further back than that, and may be seen in the fields of expert/knowledge-based systems, organisational learning and the study of business processes, to name but three.

The aim of this paper is to review both the literature on knowledge management and the practice of knowledge management in the energy sector, and to offer some views about possible future directions. In order to do that, it will also be necessary to explain some of the key general knowledge management concepts. What we shall see is that 
some parts of the energy sector are amongst the leaders in KM, especially oil and gas field exploration and development, and the operation of electricity generating plants, but other parts of the sector show little awareness of KM. Interestingly, some activities labelled within the energy sector as knowledge management appear to be going on without being informed by mainstream KM research and practice at all.

The paper is structured as follows. First, we present some KM concepts. Then, we review examples of $\mathrm{KM}$ in the energy sector before going on to draw out the most important current issues and themes, We then close by drawing some conclusions and identifying future directions for research and implementation.

\section{KM Concepts}

In this section we review the most important general KM concepts, to provide a foundation for our more specific discussion for readers who are unfamiliar with the wider KM literature.

\subsection{KM systems}

KM systems are commonly defined solely in IT terms, for example as "information systems applied to managing organizational knowledge” (Alavi and Leidner, 2001; Carlsson, 2003). Whilst a tightly-defined term may make academic discourse easier, we believe that such a definition encourages too much of a focus on the technology itself, and would be happier if this had been called by a different name such as KM technology or KM tools. Throughout this paper we shall always regard a KM system as including people, processes, technology and (potentially) structure, in a similar manner to Leavitt’s sociotechnical systems “diamond” (Leavitt, 1964).

The interactions between the three KM system elements of people, processes and technology are shown in Figure 1.

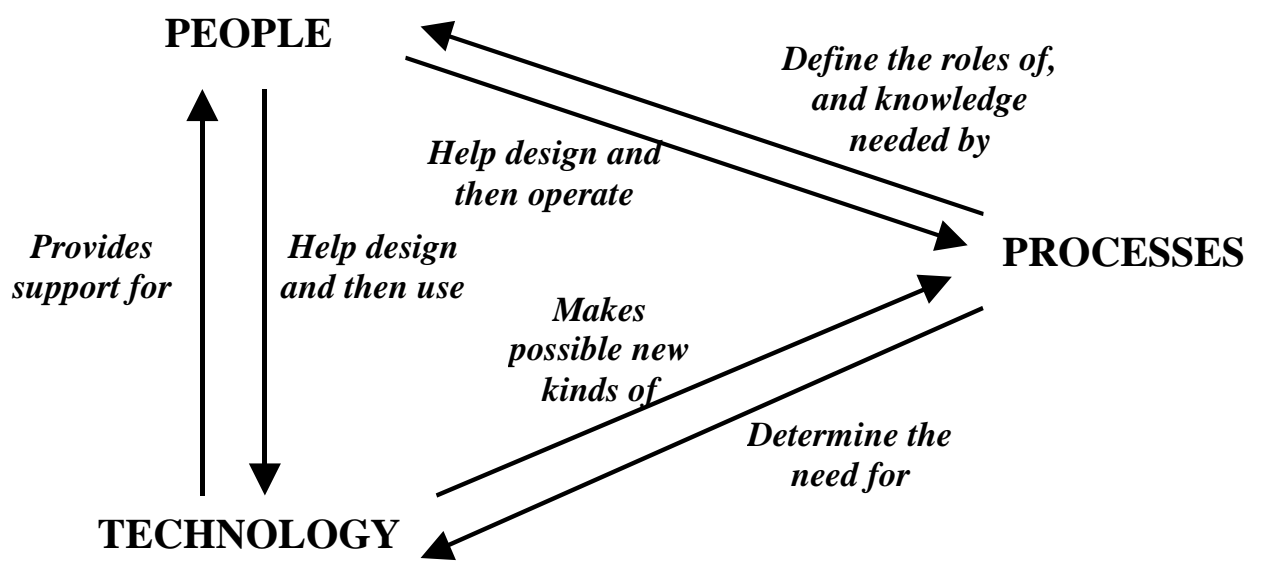

Figure 1: People, processes and technology in a KM system (Edwards, 2005)

A fundamental distinction commonly found in the KM literature is that between tacit and explicit knowledge, which in the KM field usually takes as its foundation the 
work of Polanyi (1966). One point that needs to be made very clear is that tacit and explicit knowledge are not alternatives. Rather, all knowledge has both tacit and explicit elements, as shown in Figure 2 (the size of the circles is arbitrary, for illustration). The balance between tacit and explicit knowledge changes for different items of knowledge: knowledge of how to ride a bicycle is almost entirely tacit, whereas knowledge of how to connect two pieces of equipment together is usually mainly explicit. Knowing how to release a stuck drill bit is probably somewhere inbetween. Note that there is growing tendency to refer to the "middle" circle - tacit knowledge that could be made explicit - as implicit knowledge, whereas older KM work tends to treat the phrase implicit knowledge as a synonym for tacit knowledge.

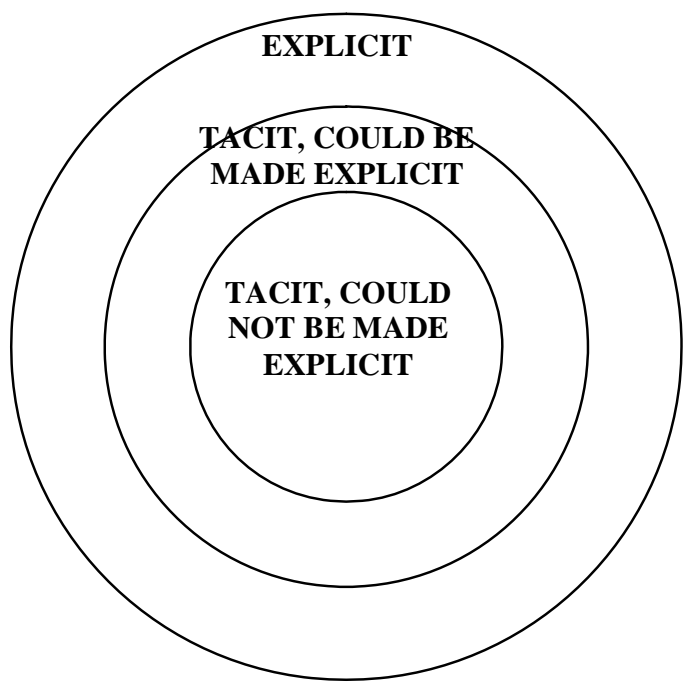

Figure 2: The relationship between tacit and explicit knowledge (Edwards, 2004)

\subsection{Personalisation and codification}

Related to both the people-technology distinction and the concepts of tacit and explicit knowledge is the broad acceptance within the literature that there are two fundamental approaches to KM strategy: those of personalisation and codification. Personalisation takes the viewpoint that an organisation's knowledge resides mainly in the heads of its people, and is mainly tacit. The main purpose of KM systems is therefore to help people locate and communicate with each other. Codification takes the viewpoint that the most relevant knowledge for the organisation can be codified and stored in computer format (i.e. made explicit), so that it may be widely shared, and that this would be the core of a KM system. These two approaches were originally identified and proposed as fundamental by Hansen et al (1999), on the basis of research conducted initially with management consulting companies.

Hansen et al (1999) went on to identify these two main KM strategies as corresponding to different competitive strategies. Personalisation fitted a competitive strategy based on creative, individual solutions to high-level problems (examples given were McKinsey \& Company, and Bain \& Company). Codification, by contrast, fitted a business strategy based on high-quality standardised solutions usually relying heavily on information systems (examples given were Andersen Consulting - now Accenture - and Ernst \& Young). 
The two approaches were not, however, proposed as being mutually exclusive. The original study found that all management consultancies (the "early adopter" first sector examined) used both personalisation and codification strategies to some extent. Nevertheless, from analysing the success of KM initiatives, Hansen et al advocated that to achieve the most effective results, an organisation should commit itself principally (say 80\%) to one strategy, with the other in a supporting role (say 20\%). A "stuck in the middle" position, such as $50 \%$ use of each strategy, was to be avoided.

\subsection{Communities of practice}

The concept of communities of practice (CoPs) was first identified by Lave and Wenger (1991) and Brown and Duguid (1991). A useful definition of CoPs is "groups of people informally bound together by shared expertise and passion for a joint enterprise” (Wenger and Snyder, 2000). They might form within an organization, or across organizational boundaries. Naturally, CoPs are likely to form a key element of any personalisation strategy towards KM. There is still debate in the literature as to whether CoPs can be "constructed", or encouraged, or merely have to be left to emerge (or not) by themselves. In our own research (Edwards et al., 2005a), we found an example where a $\mathrm{CoP}$ had arisen naturally to connect new staff with experienced staff in a research and development organisation, but even relatively limited attempts to provide more formal support for it only succeeding in killing it off.

\section{$2.4 \mathrm{ba}$}

CoPs are one example of the relevance of the concept of $b a$ to knowledge management, as expounded by Nonaka and Konno (Nonaka and Konno, 1998). The Japanese term ba has no direct translation into English, although Snowden (Snowden, 2000; Snowden and Boone, 2007) claims that the Welsh word cynefin has a similar meaning. The closest single word equivalent in English is something approximating a "place" or a "space", where people meet, but the word also has a strong cultural resonance - the slang terms "turf" and (for Londoners) "manor" capture a little of the essence of $b a$. For KM, however, there is much more to $b a$ than a physical place - it may also be virtual, spiritual, metaphorical or all of these at once.

Nonaka and his co-workers emphasise that it is vital to provide suitable $b a$ to offer a shared context in which knowledge-related activities, especially knowledge creation and organisational learning, may take place. Research on this continues (Nonaka and Toyama, 2003). Indeed, one view of KM is that this is all that needs to be done, rather than for example the provision of extensive IT-based KM systems. This remains an active debate in the KM field, sometimes over-simplified to a contrast between "Eastern" and "Western" approaches. For a more detailed discussion of the cultural aspects of KM, we recommend the article by Zhu (Zhu, 2004), a Chinese author based in the UK.

\subsection{Making KM happen}

There is general consensus in the KM literature that there is no "one right way" to make KM happen in an organisation. Naturally, this can make it seem more difficult, 
because of the need to tailor the approach taken to the needs of the organisation in question. In this section we will look at some of the key strategic elements that need to be taken into account. What does KM encompass? How do you know where you are starting from? What are you trying to achieve? Will you know it when you see it?

To address the first question, one appealing way to conceive of knowledge management activities in an organisation is in the form of a life cycle of knowledge. Unfortunately there is no general agreement in the KM literature on what that life cycle should be. Figure 3 shows one version that we have used previously (Edwards, 2001), with activities of knowledge creation, refinement, storage, transfer and use. In some contexts, it may be important to include knowledge acquisition (from outside the organisation) explicitly in the model, as an alternative to an internal process of knowledge creation. Most alternative views of the life cycle have broadly similar activities, with variations in the level of detail.

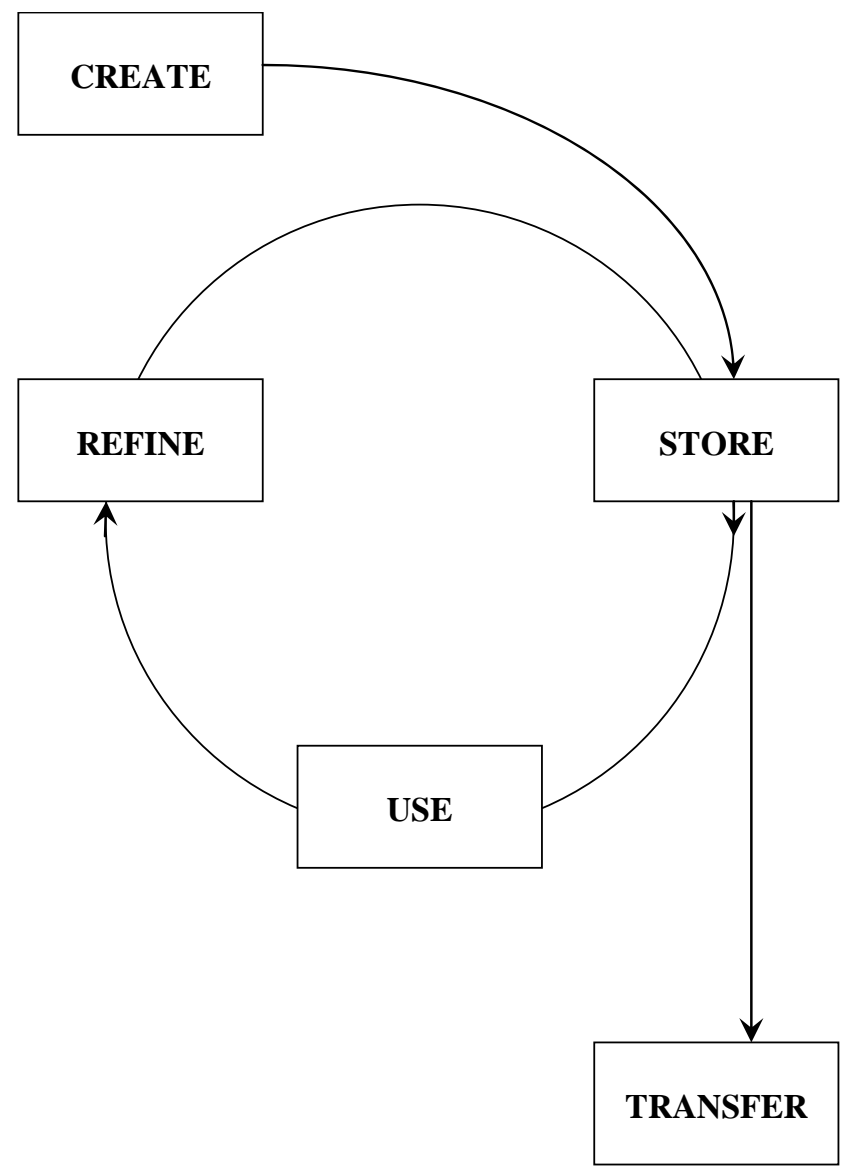

Figure 3: A knowledge management life cycle (Edwards, 2001)

Moving on to the question of where the organisation is starting from, any organisation that is completely new to KM, at least as an explicit activity, would be well advised to begin with a knowledge audit. Many tools and techniques are available for this (Hylton, 2003; Schwikkard and du Toit, 2004; De Lusignan et al., 2005; Liebowitz, 2005) and the results are often produced in the form of knowledge maps. 
What a KM initiative is trying to achieve is a question that can only be answered for a particular organisation at a particular time, but it is worth stressing that the leaders do need to make this absolutely clear, and to ensure that a consistent message is passed down to everyone involved in the initiative. Even now, some KM initiatives are still; introduced on a "me too" basis, which is unlikely to bring success. So, how will managers know it when (or if) they see it? Again, it is important to set objectives and to recognise that a major KM initiative may take several years to come to fruition. One of the influential early papers on KM pointed out that "even the most developed, mature projects we studied were unfinished" (Davenport et al., 1998) and there is no evidence that the situation has changed substantially since then.

One essential element in any KM initiative or project is to ensure that the top-down strategic direction of knowledge management in the organisation is aligned with the bottom-up organisational learning that is essential in order to make any concrete difference in the way that the organisation actually operates (Edwards and Kidd, 2003). This brings together all the aspects we have set out in this section - do the strategy and culture of the organisation better support personalisation or codification approaches? How standard are the organisation's processes? What are the key knowledge-related activities to be managed in this organisation now? Much can be learned from the experiences of others in KM, as the following sections will show, but in the end the one thing that all authors on KM agree about is that there is no "one size fits all” solution to KM problems.

\section{KM Examples in the Energy Sector}

This section gives examples of KM in the energy sector, although as we will see, not all of the projects discussed were called KM at the time.

\subsection{Oil industry}

Some parts of the oil industry have an extremely good reputation for KM, the bestknown example surely being that of BP. BP Exploration was one of the organisations mentioned in the influential early paper by Davenport et al on successful KM projects (Davenport et al., 1998), for its “virtual teamwork” approach to knowledge sharing which enabled global expertise to be brought to bear on local problems, such as trouble-shooting equipment failures.

In due course, two members of BP's successful KM team produced a book about their experiences (Collison and Parcell, 2004). A whole book about a single company is a rarity in any field, let alone KM. Amongst the novel elements in the BP approach was their cycle of "learning before, learning during and learning after". They also introduced many communities of practice and a corporate Yellow Pages system intended to help communities of practice to form and operate. Above all, however, the $\mathrm{BP}$ approach to KM relied upon building up a culture within which people were willing to share knowledge.

This culture stood them in extremely good stead when it came to the mergers which were common in the industry at this time. An article by Barrow (Barrow, 2001) concentrates on the merger between BP and Amoco. He explains how the principles 
that had already been established at BP were used when the merger took place. Sharing know-how was one of the key principles. He describes the operation of various CoPs, giving examples of 5 different "networks" (as BP call CoPs) ranging from Refinery Operations Managers to Challengers (workers new to the company). He also describes the 3D visualization technology HIVE (Highly Immersive Visualization Environment) and how it was used to help specialists with different skills (such as geologists and drilling engineers) to work together. A key point specific to mergers is that BP believes common core processes are vital in enabling the sharing of knowledge: examples are the complementary pair of the Capital Value Process and the Operations Value Process.

$\mathrm{BP}$ also stressed a holistic approach to $\mathrm{KM}$, as is clear from the title of another article, "Integral knowledge management and the energy multinational" (Coffman and Greenes, 2000) In it, Coffman interviews Greenes, who used to be head of KM at BP. This made Greenes one of the first of a new breed, the Chief Knowledge Officer (CKO). They talk especially about transfer of best practices from and to the energy sector, with Coffman saying that in pre-KM days it had been mainly inward. Greenes emphasises three aspects: how useful the KM work was in mergers and acquisitions, the value of the networks (CoPs) and the need for people who can take ownership of the KM initiatives. He also makes the point that simple tools (like a good search engine) can often provide better support for KM than complex special-purpose ones. We have confirmed this in our own research (Edwards and Shaw, 2004), and a similar result was found in the survey by Zhou and Fink (2003).

Elsewhere in the oil industry, Halliburton and Schlumberger have acquired a reputation for KM as we shall see in the next sub-section. To these we can also add Shell. The example of Shell is quoted at length in the book by Bahra (2001, p.190 onwards). The emphasis in that article is not on the energy sector per se. It concentrates instead on what one of Shell's knowledge managers, Marcus Speh Birkenkrähe, thought about KM. Particular points are that he thinks measurement in $\mathrm{KM}$ is over-rated, that trust is much more important, and that in the not-so-distant past, Shell's main approach to KM had been to relocate people from one site to another. This could perhaps be seen as one way to attempt to form CoPs. The book chapter does however identify two KM frameworks that had been used in Shell, one being a lifecycle type model of the processes involved in KM (capturing, sharing, using, learning) and the other a content-based framework divided into three parts (collaboration, content and best practices).

Reinmoeller and van Baardwijk (2005) also include Shell Petroleum as an example of good practice not specific to the energy sector, in this case as one example of sustained successful innovation amongst Dutch companies. They explain Shell's success as resulting from a combination of diversity and resilience. Leavitt (2002) mentions KM projects in Schlumberger, Chevron, Halliburton and BP Amoco.

Turning to other more specific examples of KM in the oil industry, Nelson (1997) describes the pioneering use of virtual seminars in the petroleum industry. He claims that the very first example of a web-based virtual seminar was given by him to groups of geoscientists involved in interpreting seismic results in the mid-1990s, building on earlier work using teleconferencing and video conferencing. As early as the end of 
1996, several virtual seminars were available over the web to those in the petroleum exploration and production industries.

An alternative approach to forming relatively informal CoPs (or letting them form) is to set up specific departments or units to achieve similar results. Morales et al (1999) explain the importance of a Technical Information Centre as a centre of provision of knowledge in the oil industry, using the example of PDVSA, the Venezuelan stateowned oil company.

This is not to imply that all KM initiatives are immediately successful Oliveira et al (2005) describe how, in a Brazilian Oil Company, equipment knowledge was not transferred along the manufacturing chain (as they label it) to the point where strategic decisions about extraction were actually being made. A design reengineering project was needed to solve this problem.

In the next section, we look at some more examples concerned specifically with exploration and development in the oil (and gas) industry.

\subsection{Oil/gas exploration and development}

As mentioned above, KM in the energy sector goes back a very long way - and if we go beyond KM into the heyday of expert/knowledge-based systems (KBS), one of the earliest practical examples was Dipmeter Advisor, used by Schlumberger in oil exploration. Smith and Farquhar explain how this artificial intelligence-driven work led Schlumberger into KM (Smith and Farquhar, 2000). Etkind et al (2003) explain the use of project KM portals in oilfield projects using Schlumberger's Integrated Project Management Group as the example. Their approach covers both exploration and production, and stresses the difficulties caused by having to deal with geographical dispersion and multiple specialists, the latter often working for different companies or sub-contractors. They point out that mergers often lead to the loss of experienced people. The wider literature refers to as many as one-third leaving within two years (Unger, 1988; Cartwright and Cooper, 1993). This contrasts with the approach that BP claimed to take. Interestingly, Etkind et al state "The average age of petroleum engineers is almost 50 years” (p.191). They claim that Schlumberger's KM is based on a knowledge sharing culture and give many examples. These use all of the three elements in Figure 1 to make connections, as shown in Table 1.

\begin{tabular}{|l|l|l|}
\hline \multicolumn{1}{|c|}{ Connecting... } & \multicolumn{1}{c|}{ KMS } & \multicolumn{1}{c|}{ Elements } \\
\hline people to people & online CVs system & people, technology \\
\hline people to information & project data repositories & technology \\
\hline people to CoPs & $\begin{array}{l}\text { a specific initiative } \\
\text { intended to create CoPs }\end{array}$ & process \\
\hline people to knowledge & $\begin{array}{l}\text { InTouch, a corporate } \\
\text { validated knowledge } \\
\text { repository }\end{array}$ & $\begin{array}{l}\text { people, process, } \\
\text { technology }\end{array}$ \\
\hline people to learning & HR department & people \\
\hline people to everything & project knowledge portal & people, technology \\
\hline
\end{tabular}

Table 1: Knowledge management systems in Schlumberger, based on data from (Etkind et al., 2003) 
Between them, the systems in Table 1 address all of the stages in the life cycle shown in Figure 3. For example, the project knowledge portal was used in a project in South America, both to improve the performance of the team working on the project ("use" and "refine" in Figure 3), and to enable a completely new team to take over after the project had been stopped for several months ("store" and "transfer"). Schlumberger have built so many project portals (326 in three years) that they developed their own software tool, Schlumberger DecisionPoint, to do it.

Also pre-dating the invention of the term KM is a book which looks at the organisation of the Norwegian oil industry (Stinchcombe and Heimer, 1985). Indeed, neither "knowledge" nor "learning" appears in the book's index, but it does raise some of the issues that are still relevant to KM today. These include the coordination of different professional specialists (Davison and Blackman, 2005), often working for different organisations (van den Berg and Popescu, 2005), and coping with the uncertainty of an environment which no-one has ever experienced before (Koulopoulos and Frappaolo, 1999; Pauleen et al., 2007). It also mentions one or two specialised aspects of knowledge, such as that relating to insurance for the energy sector, that no longer seem to be covered in the energy sector literature.

Norwegian sea oilfield organizational learning has continued to be an important area of KM focus. Hustad (1999) writes about Statoil and the Norne oil field deployment project. He examines organisational learning and the knowledge creation process, using Nonaka's ideas (Nonaka, 1994) which developed into the concept of $b a$. Integration of specialists from different companies was an important issue, and Hustad makes a key finding that "both redundancy and variation must be present in a knowledge development team”. The team has to have enough similarity of background and language to understand each other (redundancy as he calls it) but also needs to bring enough dissimilarity of perspective to produce new ideas. This is consistent with the results of work on team performance more generally, that teams with moderate diversity are most effective (Brodbeck et al., 2007). This theme of "medium diversity" or "sufficient variation" is also the explanation given by Reinmoeller and van Baardwijk (2005) for Shell's success, as described in the previous section. Their claim is that enough diversity is needed to be able to continue to innovate successfully in an unknown future, but not so much that no progress can be made.

Hustad also finds that Nonaka's work is well justified in the Norwegian oilfield case, as is that of George Huber on organisational learning (Huber, 1991). Hustad also speculates on whether the formal organization will maintain its role as the home of learning for the knowledge worker in the future.

Two papers describe KM at Halliburton (Behounek and Martinez, 2002; Ash, 2005). Behounek was director of Halliburton's KM programme. They had a rolling projectbased KM strategy, which is a good example of the staged approach advocated elsewhere (Edwards and Kidd, 2003) and moved from an initial technology focus to one that emphasised human issues such as CoPs. Ash discusses a community of electronic technicians at well sites. They designed their own portal so that they could function as a CoP at all times. Interestingly, organisationally KM was (in 2005) under Supply Chain and Management Systems. Behounek stresses the need for the sustainability of KM - key elements in this are trust, rewards, adaptation, value- 
generation driven, collaboration, and ensuring that $\mathrm{KM}$ is not an isolated initiative but tied into others.

Another discussion of the benefits of CoPs in oil exploration and development is that by Amin et al (2001). It regards them as crucial in developing and sustaining a knowledge sharing culture, with examples from Schlumberger, BP and briefly Chevron.

Anderson and Boulanger (2004) consider drilling as one of many aspects within lean energy management. Their main interest is in "lean" as applied to process control, and they list a whole host of actual and potential applications relevant to the energy sector, including power plants of all kinds, and electricity transmission systems and distribution networks. They consider KM based on a three-dimensional model, with dimensions of static-dynamic, context-dependent or independent and abstractionunderstanding. Onto this they superimpose other dimensions, based on the twodimensional planes at the sides of the cube formed by these three dimensions, such as the knowledge ladder hierarchy that runs data-information-knowledge and more contentiously wisdom. Their approach also emphasises the feedback loop in modelling (adaptive models) and machine learning. Their claim is that lean approaches to exploration and development require extensive modelling and simulation before implementation, with this computer-based work taking 5 times as much effort as the physical work in the field. They give a proof of concept example of lean exploration drilling, which uses machine learning adaptive models. They then hypothesise other uses, such as a system to train novice drillers, or a drilling controller decision support system (DSS).

Several papers mention other DSS for exploration and development. Corben et al (1999) describe a system dynamics model for oil field value management. They use system dynamics as the basis of an approach to capturing knowledge about all aspects of the oil field management value chain. This uses typical system dynamics causal loop diagrams as a means of knowledge representation. They give three case examples, one a "Late life field". Hesthammer and Fossen (2000) use a simulation model to assess oil and gas recovery from drilling fields. Prassl et al (2005) outline a fuzzy logic expert system for assessment of gas drilling risks. Deepwater oil and gas drilling is especially difficult in the Arctic, where the low temperatures may affect the chemistry of what is happening in the drilling process, especially the gas hydrates. At the time of their paper their process KM system (P-KMS) was a prototype.

\subsection{Power generation}

The main themes of published KM work in the power generation area are organisational learning and decision support. Carroll et al (2002) examine organisational learning in high-hazard environments, of which nuclear power plants are a good example. Carroll et al look at two aspects - individual vs collective learning, and single- and double-loop learning. They also cite Weick (1987) as pointing out that organisations such as nuclear plants, where reliability is more important than efficiency, have their own learning issues which are different from those in the mainstream organisational learning literature. The study by Carroll et al is based on problem investigation teams. They found that the teams do not have the responsibility to implement changes, and that as a result the managers and team 
members disagree about what happened. They also examine the case of Millstone, a US nuclear plant operator whom the regulator (NRC) temporarily barred from running its plants. The new CEO had to work hard to build up a culture of trust. Millstone had concentrated on the technical aspects of the plant but neglected the people factors.

Another paper where reliability is the focus of KM is that by Strater et al (2004) on $\mathrm{KM}$ and human reliability assessment. Their particular concern is with errors of commission. These are not exclusive to power generation, or indeed the energy sector, but the consequences of such errors in the nuclear power industry, such as those at Chernobyl and Three Mile Island, may be greater than in other sectors. Their paper is based on the argument that existing human reliability assessment methods do not tackle these errors well, if at all. Especially important for KM is the authors' observation that the errors of commission are generally not errors as such, in that they are "correct" but based on an incomplete or wrong understanding of the situation, or even result from employees having been trained to do the wrong thing. There is a tension between the well-defined world of the plant itself and the human world of the operators. The influence of regulation is an issue, for example, and they make the point that an ageing population (as in most Western countries, and Japan, for example) brings changing expectations about health and safety. Especially interesting from the KM viewpoint is the observation that "Nuclear is a relatively old technology. The average age of staff (as for the entire society) in industrial countries is currently increasing. Overall nuclear will be faced with the issue of loss of knowledge due to retirements".

Some of the other papers under this sub-heading can be seen as attempting to address this latter issue. For example, (Willenbockel and Tietze, 2007) discuss knowledge transfer by the nuclear technology training centre of the TUV Nord Group, which they cite as being crucial in generational change. Note however that here the generations refer to technological generations, not the age of the workforce.

More specific examples of DSS include those reported by Menal et al (2000) and Porcheron and Ricard (1999). Menal et al have developed a web-based DSS that supports the design of gas circulation (cooling) systems for the turbines in power plants (both nuclear and conventional). The knowledge in the system comprises three parts: a guide to the documents available, a model of the knowledge in the domain, and a case base. Technically this is a KBS with some case-based reasoning elements, although the authors do not use either of these terms.

Porcheron and Ricard explain the knowledge-based diagnosis of faults in Electricité de France (EdF) nuclear power plants. The technical part of this DSS seems to be a standard expert system/knowledge-based system for preserving knowledge, but its development again raises the issue of bringing together different groups of people for example, those with the knowledge about generators as a whole, those who operate a particular plant/generator, and those who designed and built the equipment originally (e.g. Alsthom for the generators). So the knowledge in the KBS is based on a CoP, not that of an individual. The overall approach in EdF is that of conditionbased maintenance, rather than fixed-time maintenance schedules. 


\subsection{Power transmission}

Power transmission should in principle offer as fruitful a field for KM as the "upstream" stages, but there are relatively few papers published in the literature. An exception is the article by Klashner and Sabet (2007), which raises issues technical, managerial and regulatory issues. Klashner and Sabet look at DSS in an electric power utility control centre. This is an extremely difficult environment, because even with 100 years of experience it is clear that it is not (and will never be) possible to find and prevent all faults. Thus human operators are a continuing crucial part of the system. They need the best real-time decision support that can be provided, but there is a major danger of information overload. Deregulation of the electricity market in the USA therefore presented both opportunities and problems for DSS software designers - for example, a narrow set of somewhat outdated Federal requirements being replaced by more flexibility but also sometimes contradictory requirements. They argue that "the recent US Northeast 2003 blackout was to a large degree propagated by incorrect decision-making arising from a dependency on ICT” (p.993). The authors go on to present an example of a grid control system. Significantly, they were unable to complete the implementation of the system because of "political" problems between the various collaborating companies over competing products that they might wish to offer.

The Coffman and Greenes article mentioned earlier (Coffman and Greenes, 2000) also includes a point about electricity utilities, where the experiences in KM from the oil sector's mergers and acquisitions was (in 2000) seen as highly relevant in the light of the opportunities presented.

\subsection{Oil Refining}

The most common examples of KM in this area are DSS in the form of expert systems/KBS. For example, Landryova and Irgens (2006) examine data systems and process knowledge in an oil refinery, in a paper mainly concentrating on the technical ICT aspects. Supervisory control and data acquisition (SCADA) open system applications are used in an oil refinery. A rule-based expert system is combined with the SCADA system to generate knowledge about the states of corrosion of the process equipment. This process knowledge is made available using specially configured SCADA screens. This DSS supports process management decisions over a wide range of equipment and physical locations.

Worth mentioning also under this heading is work in the chemical process industry (Aldea et al., 2004). They describe various prototype applications of multi-agent systems in the chemical engineering process industries. These include a web searching system, a support system for concurrent engineering design, and a team configuration support system (to help design a team to work on a new project). According to the authors there are clear similarities between the chemical process industry and the petroleum industry, and it seems evident that the web searching system and team configuration support system might well find applications in the energy sector. 


\subsection{Nuclear materials}

A very particular area of application for $\mathrm{KM}$ is in managing radioactive nuclear materials. Stoneham (2002) talks about the importance of computer modelling (and its history), pointing out that the nuclear industry and the computer industry have grown up together, and mentioning specifically the importance of modelling the lifecycle of nuclear fuel, and its implication for nuclear plant life management (knowing if it reacts with the container it is stored in for example). Seddon (2001) looks at KM in the long-term storage of nuclear materials, where knowledge needs to be retained far beyond the lifespan of a single human being

An offshoot of this topic is the relatively new field of nuclear forensics, which enables the provenance of any nuclear materials being illegally smuggled or trafficked to be traced. Heller (1993) reports on how such tracing involves the collaboration of many groups of scientists worldwide, and also of uranium producers in different areas, so that the appropriate "signatures" can be developed. Wong and Smith (2005) specifically look at KM development activities for nuclear forensics.

\subsection{Service provision/configuration}

Moving on from technical aspects, we also find KM applied to more managementrelated topics. Baida et al (2004) discuss service configuration in the Norwegian energy sector, although they do not specifically use the term KM except to cite it as the source for the term configuration (of the bundle of services). Richardson et al (2001) describe the founding of a new subsidiary of a gas and electricity utility. Inspired by deregulation in the USA, this was conceived as an Energy Service Company, with the objective of providing its customers with customised energy solutions all the way up to (dedicated) power plants. They therefore needed a new type of person from the existing staff in the "pre-deregulation" organisation, and chose to tackle this as an organisational learning challenge rather than one to be solved by "new hires". Richardson et al advocate a Singerian approach to organisational learning, which they identify as having the following properties: it is teleological, holistic, systemic, and ethical; it uses both incremental and radical change; it relies on measurement; and it takes place in an open and co-operative environment.

\subsection{Environmental awareness}

The environmental impact of the energy sector has been a major strategic issue for many years, but the potential for KM to help address these challenges is not reflected in the literature. An example of this is a paper on environmental awareness training in the electricity industry (Perron et al., 2006). The authors study the effectiveness of environmental awareness training in two Canadian electricity companies. The effectiveness in the company whose workers had been trained was not significantly better than in the one where they had not. The employees felt better about their knowledge, but were not actually any more effective in action. The authors' proposition is that the workforce were not sufficiently well equipped to receive the training. This is consistent with two classic KM concepts: absorptive capacity (Cohen and Levinthal, 1990) and "sticky" knowledge (Huber, 2000; Brown and Duguid, 
2001; Coakes et al., 2004) but neither these references nor any other KM work is cited in their paper. We will return to this issue in the next section.

\section{Issues and Themes}

We will use two papers from 2001 to help us draw out the issues and themes for KM in the energy sector.

Schafer, writing about the oil industry (Schafer, 2001), concluded that it was possible to define a new wave of $\mathrm{KM}$ - the emphasis shifting from internal and explicit knowledge, and on using data to make better decisions, to external and more tacit knowledge, and focusing on value for the customer and the use of knowledge. This view was consistent with what was happened in KM in other sectors at that time (Newell et al., 2002; Firestone and McElroy, 2003).

Also in 2001 came the concept of the "T-shaped manager" (Hansen and von Oetinger, 2001). Hansen and von Oetinger based this concept, which they then (2001) saw as KM's next generation, on the experience of BP Amoco. The T shape works out like this: the horizontal bar of the T represents willingness to share knowledge across the organisation, while the vertical bar simultaneously represents desire to achieve maximum performance from the manager's own business unit. The importance of a knowledge sharing culture is evident, and the mergers of Amoco and ARCO with BP are cited as successful examples. Hansen and von Oetinger describe the T-shaped manager in three words as "a human portal"! However, the point is made that it is possible to overdo knowledge sharing, even though the benefits of it are clear. For example, BP's networks/CoPs could get out of hand, so that too much time is spent in meetings of CoPs and not enough time actually doing things. Hansen and von Oetinger summarise five ways in which T-shaped managers help their organisations: increasing efficiency through the transfer of best practices; improving the quality of decisions through peer advice; growing revenue through shared expertise; developing new business opportunities through the cross-pollination of ideas; making bold strategic moves through the promise of well coordinated implementation.

With the benefit of hindsight, it is clear that Schafer's predictions were correct, although with the side-effect that some of the more technical, internal projects are no longer labelled KM as they once would have been. Similarly, Hansen and von Oetinger have described the desirable capabilities of a good $21^{\text {st }}$ century manager, although their terminology does not seem to have caught on widely. It is also not always easy to find the time away from operational matters to make these improvements happen.

Drawing on these and the other papers we have reviewed, the following issues/themes are apparent:

- the importance of knowledge sharing at all levels

- the need to create and sustain an appropriate culture for KM in the organisation

- the requirement to balance similarity and difference in teams in order to promote both performance and creativity

- making the right use of technology 
Returning to Figure 1, let us consider these developments in the light of the three elements of People, Processes and Technology. This will be done in an integrated manner, rather than under separate headings, since all three elements need to be addressed in any KM initiative. First, the balance between the three elements has clearly changed over time. As the above themes demonstrate, there has been a definite shift in emphasis in KM from the Technology element and towards the People element. The many authors who advocated this shift will no doubt feel this was entirely the right thing to do. However, the downside of this change has been that there has also tended to be less attention paid to Processes. One reason for this may well be that recent developments in Business Process Management generally have tended to concentrate on IT, fostering the belief that Processes are only a subset of the sphere of Technology. However, a few references in the wider KM field (Chen, 2004; Kalpic and Bernus, 2006) demonstrate that this need not be the case, and that design is just as important for human-centred processes as for IT-centred ones.

To stress the importance of this, the main challenge for many managers is not knowing what needs to be done to "do the right thing", but finding time to do it - and especially to think about it before, during and after doing it. The importance of middle managers, as the people in the organisation most likely to be able to achieve this, has been stressed in the KM literature (Nonaka and Takeuchi, 1995; Huy, 2001). More recent work by Kodama (2007) adds a further dimension, namely that middle managers need to have improvisation skills, in order to achieve the well-coordinated implementation advocated by Hansen and von Oetinger. This has both Process and People consequences. Processes are, quite literally, how any ideas or plans - strategy, projects, initiatives - are implemented. Time must be taken to design them effectively. Yet Processes cannot completely substitute for People. As we have seen, mergers are common in the energy sector, and no doubt will remain so in the future. $\mathrm{BP}$ found that common core Processes can make these mergers much more straightforward. However, mergers can also lead to the loss of experienced people, and middle managers are often seen as prime candidates to be the first to go. Yet who else can make the effective connections between strategy and operations that the organisation needs to have?

Properly applied Technology can still be crucial in KM, but on its own will never lead to success. We have given many examples of specific systems for KM or decision support in this paper, but there is a good deal of evidence that "everyday" IT familiar to the People who use it (such as e-mail, shared databases and Intranets) is at least as important for KM, if not more so (Zhou and Fink, 2003; Edwards et al., 2005b).

One Process that is conspicuous by its absence in most accounts of KM in the energy sector is the knowledge audit. This ought to be a vital element of any organisation's KM initiative. The lack of mention is perhaps the result of a comparatively large gap between the early adopters of KM in the energy sector and the rest. The early adopters will have done their knowledge audits a long time ago - so long ago that it is "obvious" to them - and this is a lesson that may not have been passed on to organisations newer to KM. There are still many of the latter in the energy sector, especially in countries of the former Soviet bloc. It is a mistake to assume that the $\mathrm{KM}$ issues and challenges that another organisation has faced automatically apply to your own organisation, even within the same industry. 
The available "solutions" may also change. The promotion of Communities of Practice (CoPs) - strongly People-centred - has been one of the most successful ways in which organisations in the energy sector (and elsewhere) have tackled the issues of promoting knowledge sharing and encouraging a KM culture. One of the links shown in Figure 1 is that Technology makes possible new kinds of Processes. As social networking systems become more and more part of the everyday fabric of society, it may be that a fundamental change in Processes is occurring and that other forms of $b a$ will become more appropriate for KM in the (near) future.

One final point is particularly relevant in emphasising the importance of the objective of this journal (IJESM) to be holistic. In preparing this review, the fragmentation of the literature on the energy sector is very apparent. We mentioned earlier that journals with an "environmental" focus such as the Journal of Cleaner Production do not seem to be informed by the KM literature. In a different part of the field, a recent paper (Yanagisawa et al., 2006) presents an evaluation of nuclear knowledge management in Japan, but again does not seem to be informed by mainstream KM at all; indeed this is true of the International Journal of Nuclear Knowledge Management as a whole.

\section{Concluding Remarks}

Although a few aspects of knowledge management in the energy sector are sectorspecific, noticeably the need to manage knowledge on relatively long timescales, most issues are common to organisations in all sectors. The drivers for these include globalisation, climate change and other environmental issues, and an ageing population and workforce in many industrialised countries. There is a need for holistic, systemic, integrated approaches to deal with the ever-increasing complexity of organisations, and indeed this was one of the reasons behind the founding of this IJESM journal. The three elements of People, Processes and Technology must all be balanced appropriately to deliver effective KM.

What a particular organisation is looking for will depend upon where it is in the "KM journey". Some organisations in the energy sector have earned a reputation as leaders in KM, such as BP: others are still completely new to KM. For those which are new to $\mathrm{KM}$, this paper has covered some of the great diversity of possibilities available. The challenge for managers is to design initiatives that fit the needs of their own

organisation now. BP's advice to "learn before, learn during and learn after" is a good starting point.

For those nearer to the leading edge of KM, we have discussed future directions in general KM research and practice elsewhere (Edwards, 2008). The greatest challenge for researchers is to work to unify the still-divergent theoretical base of KM: until this happens (and it may be a very long way off) it is essential that researchers state their definitions and assumptions clearly. Considering the energy sector more specifically, there are four key aspects.

The first is the need to address generational issues, of three kinds: the ageing population (and therefore workforce) in many countries; the possibility that people under 25 operate in different social structures, enabled by social networking technologies, from those of older workers; and generational change in the industry 
itself. In particular, new sources of energy will require new Processes, not just new Technology, and perhaps also new (or at least differently trained and educated) People. This presents both threats (loss of experienced staff, incompatible data formats in old and new computer systems) and opportunities (codification, longerterm CoPs including retired staff, systematic project based learning) for KM.

The second is not to neglect theories simply because they are unfashionable or have fallen out of favour. Knowledge-based systems and the associated techniques of knowledge elicitation are a good example of this. There are many examples of successful KBS in the energy sector, as we have indicated, but the reputation that these systems have in some quarters has led to some of the lessons that should have been learned from their development - especially about how to make knowledge explicit - being overlooked.

The third is to look at the theories on offer in the broader field of KM. Some parts of the energy sector are very insular. There is much to be gained from looking at what has been tried in other sectors: studying the wider theory on knowledge sharing and organisational learning, for example.

Finally, new theories are increasing in influence within KM. These include the movement of complexity theories into the mainstream (Snowden and Boone, 2007) and the knowledge-based view of the firm, developed originally by Grant (1997). These may be worth taking on board.

To sum up, our overall verdict on knowledge management in the energy sector is "OK, but could do better". There is no doubt that knowledge in the energy sector needs to be managed, but some organisations have tackled this overtly and effectively whilst others have not addressed it at all. Specific KM issues in the energy sector include how to help maintain organisational memory over periods of decades, and how to adapt knowledge sharing practices into organisations in countries where this has not previously been part of the culture, such as those which were formerly part of the Soviet Union.

\section{References}

Alavi, M. and Leidner, D. E. (2001) "Review: Knowledge management and knowledge management systems: Conceptual foundations and research issues". MIS Quarterly, Vol 25, No. 1, pp107-136.

Aldea, A., Banares-Alcantara, R., Jimenez, L., Moreno, A., Martinez, J. and Riano, D. (2004) "The scope of application of multi-agent systems in the process industry: three case studies". Expert Systems with Applications, Vol 26, No. 1, pp39-47.

Amin, A., Bargach, S., Donegan, J., Martin, C., Smith, R., Burgoyne, M., Censi, P., Day, P. and Kornberg, R. (2001) "Building a knowledge-sharing culture". Oilfield Review, 48-65.

Anderson, R. and Boulanger, A. (2004) "Knowledge management and computational learning for lean energy management". Oil \& Gas Journal, Vol 102, No. 44, pp36-40. 
Ash, J. (2005) "Halliburton: A sustained commitment to collaboration". Inside Knowledge, Vol 8, No. 6, pp.

Bahra, N. (2001) Competitive Knowledge Management. Palgrave, Houndmills.

Baida, Z., Gordijn, J., Saele, H., Morch, A. Z. and Akkermans, H. (2004) "Energy services: A case study in real-world service configuration" in Advanced Information Systems Engineering, Proceedings, Vol. 3084. pp36-50.

Barrow, D. C. (2001) "Sharing know-how at BP Amoco". Research-Technology Management, Vol 44, No. 3, pp18-25.

Behounek, M. and Martinez, M. R. (2002) "A tour of a successful knowledge management strategy". Journal of Petroleum Technology, Vol 54, No. 11, pp33-35.

Brodbeck, F. C., Guillaume, Y. R. F. and Lee, N. (2007) Diversity as a Multilevel Construct: Predicting Crosslevel Interaction Effects on Group Member Performance. Aston Business School, Birmingham, U.K.

Brown, J. S. and Duguid, P. (1991) "Organizational learning and communities-of practice: Toward a unified view of working, learning and innovation". Organization Science, Vol 2, 40-57.

Brown, J. S. and Duguid, P. (2001) "Knowledge and organization: A social-practice perspective". Organization Science, Vol 12, No. 2, pp198-213.

Carlsson, S. A. (2003) "Knowledge managing and knowledge management systems in inter-organizational networks". Knowledge and Process Management, Vol 10, No. 3, pp194-206.

Carroll, J. S., Rudolph, J. W. and Hatakenaka, S. (2002) "Learning from experience in high-hazard organizations" in Research In Organizational Behavior, Vol 24, Vol. 24. pp87-137.

Cartwright, S. and Cooper, C. L. (1993) "Of mergers, marriage and divorce: The issues of staff retention". Journal of Managerial Psychology, Vol 8, No. 6, pp7-10.

Chen, P. (2004) "Developing knowledge management systems in BPM context" in Constructing the Infrastructure for the Knowlege Economy: Methods and Tools, Theory and Structure (Eds, Linger, H., Fisher, J., Wojtkowski, W., Wojtkowski, W. G., Zupancic, J., Vigo, K. and Arnold, J.), pp455-467.

Coakes, E., Bradburn, A. and Sugden, G. (2004) "Managing and leveraging knowledge for organisational advantage". Knowledge Management Research \& Practice, Vol 2, No. 2, pp118.

Coffman, P. and Greenes, K. (2000) "Networking know-how: Integral knowledge management (KM) and the energy multinational". Oil \& Gas Journal, 5-7.

Cohen, W. M. and Levinthal, D. (1990) "Absorptive capacity: a new perspective on learning and innovation". Administrative Science Quarterly, Vol 35, No. 1, pp128-152.

Collison, C. and Parcell, G. (2004) Learning to Fly: Practical knowledge management from some of the world's leading organizations. Capstone, Chichester.

Corben, D., Stevenson, R. and Wolstenholme, E. F. (1999) "Holistic oil field value management: using system dynamics for 'intermediate level' and 'value-based' modelling in the oil industry". Journal of the Operational Research Society, Vol 50, No. 4, pp383-391.

Davenport, T., DeLong, D. and Beers, M. (1998) "Successful knowledge management projects". Sloan Management Review, Vol 39, No. 2, pp43-57. 
Davenport, T. H. and Prusak, L. (1998) Working knowledge : how organizations manage what they know. Harvard Business School Press, Boston, Mass.

Davison, G. and Blackman, D. (2005) "The role of mental models in innovative teams". European Journal of Innovation Management, Vol 8, No. 4, pp409423.

De Lusignan, S., Wells, S., Shaw, A., Rowlands, G. and Crilly, T. (2005) "A knowledge audit of the managers of primary care organizations: top priority is how to use routinely collected clinical data for quality improvement". Medical Informatics and the Internet in Medicine, Vol 30, No. 1, pp69-80.

Edwards, J. S. (2001) Knowledge Life-Cycles: What to Keep and What to Throw Away? In Proceedings of Knowledge Management in O.R. Groups Farnborough, U.K.

Edwards, J. S. (2004) Knowledge Management Systems and Business Processes. In Proceedings of Technology Creation Based on Knowledge Science: Theory and Practice Japan Advanced Institute of Science and Technology, Ishikawa, Japan, pp. 30-38.

Edwards, J. S. (2005) "Business processes and knowledge management" in Encyclopedia of Information Science and Technology, Vol. I. (Ed, KhosrowPour, M.) Idea Group, Hershey, PA, pp350-355.

Edwards, J. S. (2008) "Editorial". Knowledge Management Research \& Practice, Vol 6, No. 1, pp1-4.

Edwards, J. S., Collier, P. M. and Shaw, D. (2005a) Knowledge management and its impact on the management accountant. CIMA, London.

Edwards, J. S. and Kidd, J. B. (2003) "Knowledge Management sans frontières". Journal of the Operational Research Society, Vol 54, No. 2, pp130-139.

Edwards, J. S. and Shaw, D. (2004) Supporting Knowledge Management with IT. In Proceedings of Decision Support in an Uncertain and Complex World: Proceedings of the 2004 IFIP WG8.3 International Conference on Decision Support Systems DSS2004 (Eds, Meredith, R., Shanks, G., Arnott, D. and Carlsson, S.) Monash University, Tuscany, Italy, pp. 233-242.

Edwards, J. S., Shaw, D. and Collier, P. M. (2005b) "Knowledge Management Systems: Finding a Way with Technology". Journal of Knowledge Management, Vol 9, No. 1, pp113-125.

Etkind, J., Bennaceur, K., Dmec, M. and Luppens, C. (2003) Knowledge Portals Support Widely Distributed Oilfield Projects. In Proceedings of IEEE International Professional Communication Conference IEEE, Orlando, Fla, pp. 189-200.

Firestone, J. M. and McElroy, M. W. (2003) Key issues in the new knowledge management. Butterworth-Heinemann, Amsterdam.

Grant, R. M. (1997) "The knowledge based view of the firm: Implications for management practice". Long Range Planning, Vol 30, No. 3, pp450-454.

Hansen, M. T., Nohria, N. and Tierney, T. (1999) "What's your strategy for managing knowledge?" Harvard Business Review, Vol 77, No. 2, pp106-116.

Hansen, M. T. and von Oetinger, B. (2001) "Introducing T-shaped managers Knowledge management's next generation". Harvard Business Review, Vol 79, No. 3, pp106-116.

Heller, F. (1993) "Another Look at Action Research". Human Relations, Vol 46, No. 10, pp1235-1242.

Hesthammer, J. and Fossen, H. (2000) "Uncertainties associated with fault sealing analysis". Petroleum Geoscience, Vol 6, No. 1, pp37-45. 
Huber, G. P. (1991) "Organizational Learning: The Contributing Processes and the Literatures". Organization Science, Vol 2, 88-115.

Huber, G. P. (2000) Transferring Sticky Knowledge: Suggested solutions and needed studies. In Proceedings of Knowledge Management beyond the Hype: Looking towards the new millennium. Proceedings of KMAC 2000 (Eds, Edwards, J. S. and Kidd, J. B.) Operational Research Society, Birmingham, pp. 12-22.

Hustad, W. (1999) "Expectational learning in knowledge communities". Journal of Organizational Change Management, Vol 12, No. 5, pp405-418.

Huy, Q. N. (2001) "In praise of middle managers". Harvard Business Review, Vol 79, No. 8, pp72-79.

Hylton, A. (2003) A KM initiative is unlikely to succeed without a knowledge audit. In Proceedings of Proceedings of KMAC2003, the Knowledge Management Aston Conference (Ed, Edwards, J. S.) Operatonal Research Society, Birmingham, UK, pp. 7-16.

Kalpic, B. and Bernus, P. (2006) "Business process modeling through the knowledge management perspective". Journal of Knowledge Management, Vol 10, No. 3, pp40-56.

Klashner, R. and Sabet, S. (2007) "A DSS design model for complex problems: Lessons from mission critical infrastructure". Decision Support Systems, Vol 43, No. 3, pp990-1013.

Kodama, M. (2007) Knowledge Innovation: Strategic management as practice. Edward Elgar, Cheltenham, UK and Northampton, MA, USA.

Koulopoulos, T. M. and Frappaolo, C. (1999) Smart Things To Know About Knowledge Management. Capstone, Oxford.

Landryova, L. and Irgens, C. (2006) "Process knowledge generation and knowledge management to support product quality in the process industry by supervisory control and data acquisition (SCADA) open systems". Production Planning \& Control, Vol 17, No. 2, pp94-98.

Lave, J. and Wenger, E. C. (1991) Situated Learning: Legitimate Peripheral Participation. Cambridge University Press, New York.

Leavitt, H. J. (1964) "Applied Organization Change in Industry: structural, technical and human approaches" in New Perspectives in Organization Research (Eds, Cooper, W. W., Leavitt, H. J. and Shelly, M. W. I.) John Wiley, New York, pp55-71.

Leavitt, P. (2002) Applying Knowledge Management to Oil and Gas Industry Challenges. American Productivity and Quality Center.

Liebowitz, J. (2005) "Linking social network analysis with the analytic hierarchy process for knowledge mapping in organizations". Journal of Knowledge Management, Vol 9, No. 1, pp76.

Menal, J., Moyes, A., McArthur, S., Steele, J. A. and McDonald, J. (2000) "Gas circulator design advisory system: A web based decision support system for the nuclear industry" in Intelligent Problem Solving: Methodologies and Approaches, Prodeedings, Vol. 1821. pp160-167.

Morales, A., Marrero, C. and Aguero, M. A. (1999) "Management knowledge and the technical information center of PDVSA-Intevep". Vision Tecnologica, Vol 7, No. 1, pp47-52.

Nelson, H. R. (1997) "Virtual seminars". Computers \& Geosciences, Vol 23, No. 5, pp601-606.

Newell, S., Robertson, M., Scarbrough, H. and Swan, J. (2002) Managing knowledge work. Palgrave, Basingstoke. 
Nonaka, I. (1994) "A Dynamic Theory of Organizational Knowledge Creation". Organization Science, Vol 5, No. 1, pp14-37.

Nonaka, I. and Konno, N. (1998) "The concept of "ba": Building a foundation for knowledge creation". California Management Review, Vol 40, No. 3, pp40-54.

Nonaka, I. and Takeuchi, H. (1995) The Knowledge-Creating Company, How Japanese Companies Create the Dynamics of Innovation. Oxford University Press, New York and Oxford.

Nonaka, I. and Toyama, R. (2003) "The knowledge-creating theory revisited: knowledge creation as a synthesizing process". Knowledge Management Research \& Practice, Vol 1, No. 1, pp2-10.

Oliveira, J., de Souza, J. M., Lima, M. and Farias, R. (2005) "GCE: Knowledge management applied in a design reengineering process" in Cooperative Design, Visualization, and Engineering, Proceedings, Vol. 3675. (Ed, Luo, Y.), pp94-102.

Pauleen, D. J., Corbitt, B. and Yoong, P. (2007) "Discovering and articulating what is not yet known: Using action learning and grounded theory as a knowledge management strategy". The Learning Organization, Vol 14, No. 3, pp222-240.

Perron, G. M., Cote, R. P. and Duffy, J. F. (2006) "Improving environmental awareness training in business". Journal of Cleaner Production, Vol 14, No. 6-7, pp551-562.

Polanyi, M. (1966) The tacit dimension. Doubleday, Garden City, N.Y.

Porcheron, M. and Ricard, B. (1999) "Towards a unified framework for knowledgebased diagnosis support of power plant devices". Engineering Intelligent Systems for Electrical Engineering and Communications, Vol 7, No. 4, pp183189.

Prassl, W. F., Peden, J. M. and Wong, K. W. (2005) "A process-knowledge management approach for assessment and mitigation of drilling risks". Journal of Petroleum Science and Engineering, Vol 49, No. 3-4, pp142-161.

Reinmoeller, P. and van Baardwijk, N. (2005) "The link between diversity and resilience". MIT Sloan Management Review, Vol 46, No. 4, pp61-65.

Richardson, S. M., Courtney, J. F. and Paradice, D. B. (2001) "An assessment of the Singerian inquiring organizational model: Cases from academia and the utility industry". Information Systems Frontiers, Vol 3, No. 1, pp49-62.

Schafer, P. S. (2001) "Knowledge management - Overview". Journal of Petroleum Technology, Vol 53, No. 9, pp82-82.

Schwikkard, D. B. and du Toit, A. S. A. (2004) "Analysing knowledge requirements: a case study". Aslib Proceedings, Vol 56, No. 2, pp104-111.

Seddon, W. (2001) "Engineering considerations associated with plants used for storage of intermediate-level waste - a regulator's view". Nuclear EnergyJournal of the British Nuclear Energy Society, Vol 40, No. 1, pp59-64.

Smith, R. G. and Farquhar, A. (2000) "The road ahead for knowledge management An AI perspective". Ai Magazine, Vol 21, No. 4, pp17-40.

Snowden, D. (2000) Cynefin, a sense of time and place: an ecological approach to sense making and learning in formal and informal communities. In Proceedings of KMAC2000 (Eds, Edwards, J. S. and Kidd, J. B.) Operational Research Society, Birmingham, UK, pp. 1-11.

Snowden, D. J. and Boone, M. E. (2007) "A Leader's Framework for Decision Making". Harvard Business Review, Vol 85, No. 11, pp68-76. 
Stinchcombe, A. L. and Heimer, C. A. (1985) Organization theory and project management : administering uncertainty in Norwegian offshore oil. Norwegian University Press, Oslo.

Stoneham, A. M. (2002) "Computational physics: a perspective". Philosophical Transactions of the Royal Society of London Series a-Mathematical Physical and Engineering Sciences, Vol 360, No. 1795, pp1107-1121.

Strater, O., Dang, V., Kaufer, B. and Daniels, A. (2004) "On the way to assess errors of commission". Reliability Engineering \& System Safety, Vol 83, No. 2, pp129-138.

Unger, H. (1988) "The people trauma of major mergers". Journal of Industrial Management, Vol 10, 17.

van den Berg, C. and Popescu, I. (2005) "An experience in knowledge mapping". Journal of Knowledge Management, Vol 9, No. 2, pp123-128.

Weick, K. E. (1987) "Organizational culture as a source of high reliability". California Management Review, Vol 29, No. 2, pp112-127.

Wenger, E. C. and Snyder, W. M. (2000) "Communities of practice: The organizational frontier". Harvard Business Review, Vol Jan-Feb, 139-145.

Willenbockel, I. and Tietze, U. (2007) "4 years of successful knowledge transfer - the nuclear technology training center of the TUV Nord Group". AtwInternational Journal for Nuclear Power, Vol 52, No. 2, pp85-+.

Wong, F. M. G. and Smith, D. K. (2005) "Recent knowledge management development activities for nuclear forensics and attribution". Abstracts of Papers of the American Chemical Society, Vol 230, U2306-U2306.

Yanagisawa, K., Yonezawa, M. and Sawada, T. (2006) "The nuclear knowledge management, its present status and tasks". Journal of the Atomic Energy Society of Japan, Vol 48, No. 2, pp113-118.

Zhou, A. Z. and Fink, D. (2003) "Knowledge Management and Intellectual Capital: An empirical examination of current practice in Australia". Knowledge Management Research \& Practice, Vol 1, No. 2, pp86-94.

Zhu, Z. (2004) "Knowledge management: towards a universal concept or crosscultural contexts?" Knowledge Management Research \& Practice, Vol 2, No. 2, pp67-79. 